\title{
EUS-FNA of a portal vein thrombosis in a patient with a hidden hepatocellular carcinoma: confirma- tion technique after contrast-enhanced ultrasound
}

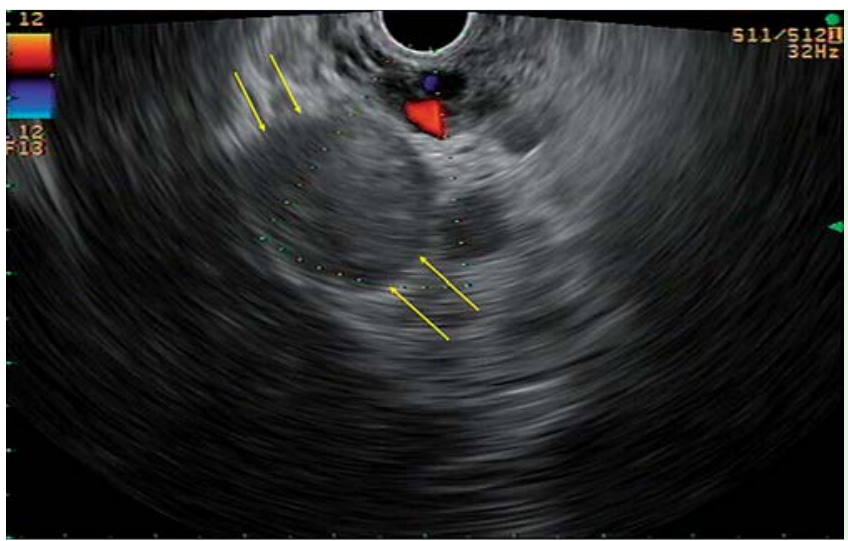

Fig. 1 Endoscopic ultrasound view of a portal vein thrombus in a patient with a hidden hepatocellular carcinoma (arrows).

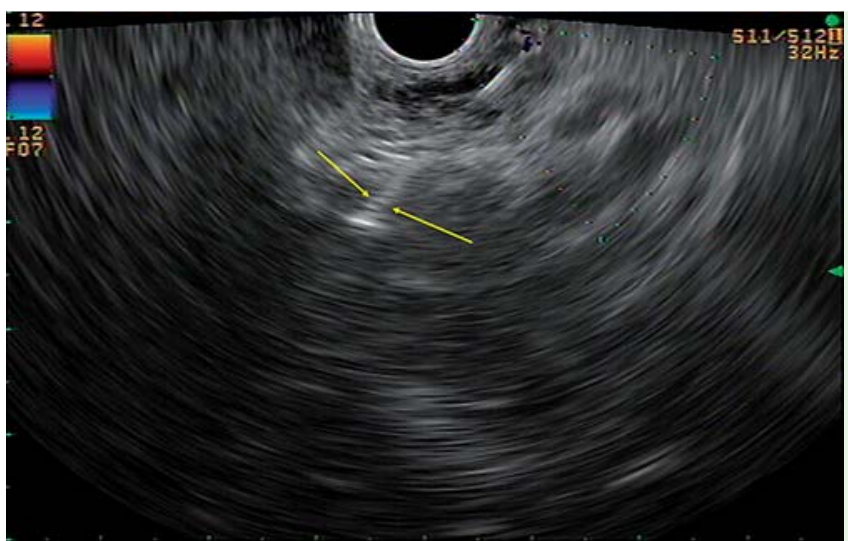

Fig. 2 Endoscopic ultrasound-guided fine-needle aspiration of the portal vein thrombus at the level of the hilum of the liver (arrows).

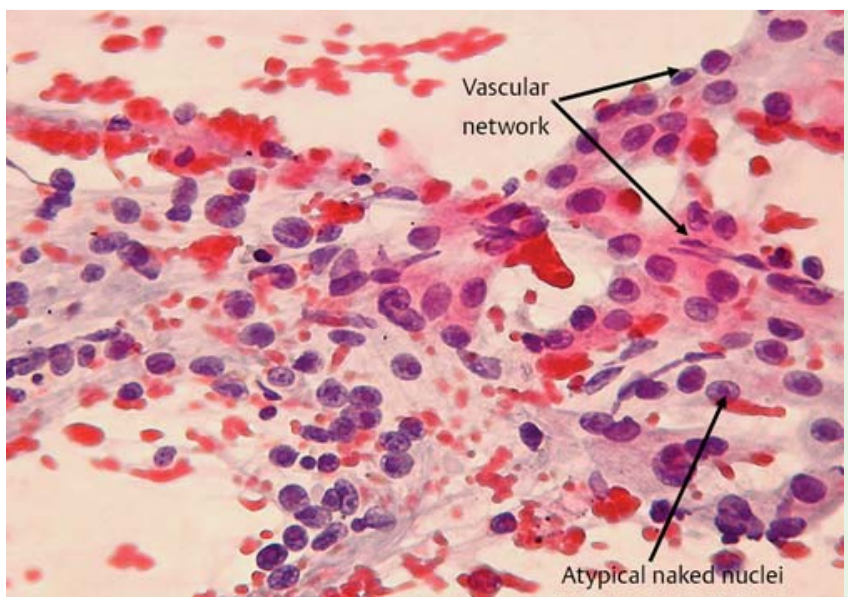

Fig. 3 Endoscopic ultrasound-guided fine-needle aspiration sample showing malignant liver cells, characterized by atypical naked nuclei with prominent and eosinophilic nucleoli (arrow). On cytologic assessment, a vascular network throughout the sheet (arrows) forms a central endothelial pattern (Papanicolaou stain, $\times 200)$.

The differentiation of a malignant from a benign portal vein thrombosis is of paramount importance in the management of a patient with cirrhosis and a potentially curable hepatocellular carcinoma. Contrast-enhanced ultrasound has led to significant progress in the diagnosis of malignant portal vein thrombosis [1]. More invasive techniques, such as transabdominal ultrasound-guided fine-needle aspiration cytology (TUS-FNA), have proved to be feasible in this setting, but they are not without complications and are sometimes technically not possible [1]. The use of endoscopic ultrasound-guided fineneedle aspiration cytology (EUS-FNA) has been rarely reported in this setting $[2,3]$, but in no case after inconclusive results of contrast-enhanced ultrasound.

A 61-year-old man with cirrhosis and a portal vein thrombosis spreading from the hilum to the right branch was admitted to our hospital. No liver mass was disclosed by computed tomography or magnetic resonance imaging. The alpha-fetoprotein level was $2.6 \mathrm{ng} / \mathrm{mL}$. Contrast-enhanced ultrasound showed arterial phase enhancement of the thrombus, suggesting a malignant origin, but concerns arose because of the absence of a liver mass. The presence of a collateral circulation and ascites precluded TUS-FNA. EUS-FNA was performed with a double purpose: to rule out hepatocellular carcinoma and for staging. The thrombus was sampled with a 22-gauge FNA needle ( $\bullet$ Fig. 1, $\bullet$ Fig. 2 ). Invasion of the portal vein by hepatocellular carcinoma was confirmed by cytologic assessment ( Fig. 3, $\bullet$ Fig. 4).

In the era of the noninvasive assessment of hepatocellular carcinoma with crosssectional imaging and contrast enhancement techniques, FNA continues to play a role. EUS-FNA overcomes the limitations of TUS-FNA. Because of the proximity of the needle to the portal vein, an excellent view of the liver hilum is obtained that facilitates needling of the portal vein thrombosis [4]. Obesity does not interfere with this view, and the proximity of the needle to the portal vein may reduce the risk for complications, such as bile duct injury, bleeding, and needle tract metastasis [4].

Endoscopy_UCTN_Code_TTT_1AS_2AG

Competing interests: None

Miguel Moreno', *, Antonio Z. GimenoGarcía $^{1,2, *}$, María Martín Corriente ${ }^{3}$, David Nicolás-Pérez ${ }^{1}$, Alejandro BritoGarcía $^{3}$, Candelaria García-Castro ${ }^{3}$, Enrique Quintero ${ }^{1,2}$

Servicio de Gastroenterología, Hospital Universitario de Canarias, Tenerife, Spain ${ }^{2}$ Instituto Universitario de Tecnologías Biomédicas (ITB) and Centro de Investigación Biomédica de Canarias (CIBICAN), Departamento de Medicina Interna, Universidad de La Laguna, Tenerife, Spain 3 Servicio de Anatomía Patológica, Hospital Universitario de Canarias, Tenerife, Spain

\footnotetext{
* Miguel Moreno and Antonio Z. Gimeno-García contributed equally to this work.
} 


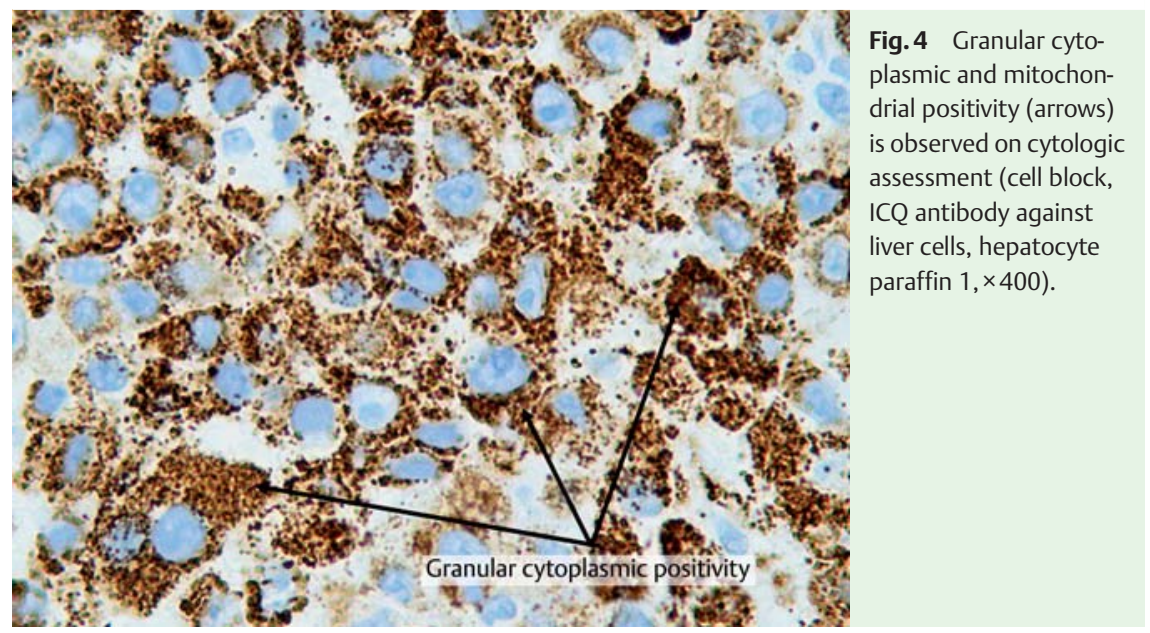

\section{References}

1 Tarantino L, Francica G, Sordelli I et al. Diagnosis of benign and malignant portal vein thrombosis in cirrhotic patients with hepatocellular carcinoma: color Doppler US, contrast-enhanced US, and fine-needle biopsy. Abdom Imaging 2006; 31: 537 - 544

2 Storch I, Gomez C, Contreras F et al. Hepatocellular carcinoma (HCC) with portal vein invasion, masquerading as pancreatic mass, diagnosed by endoscopic ultrasound-guided fine needle aspiration (EUS-FNA). Dig Dis Sci 2007; 52: 789-791
3 Lai $R$, Stephens $V$, Bardales $R$. Diagnosis and staging of hepatocellular carcinoma by EUSFNA of a portal vein thrombus. Gastrointest Endosc 2004; 59: 574-577

4 Gimeno-Garcia AZ, Elwassief A. How to improve the success of endoscopic ultrasound guided fine needle aspiration cytology in the diagnosis of pancreatic lesions. J Interv Gastroenterol 2012; 2: 31-36
Bibliography

DOI http://dx.doi.org/

10.1055/s-0034-1390734

Endoscopy 2014; 46: E590-E591

(c) Georg Thieme Verlag KG

Stuttgart · New York

ISSN 0013-726X

\section{Corresponding author}

\section{Antonio Z. Gimeno-García, MD}

Hospital Universitario de Canarias Unidad de Endoscopia (10 planta), Departamento de Gastroenterología Ofra s/n 38320 La Laguna Tenerife

Spain

Fax: +34 922678554

antozeben@gmail.com 